\title{
Sociologías del espacio: \\ legado teórico \\ y productividad empírica
}

Miguel Martínez López

Universidade da Coruña

miguelm@udc.es

\section{RESUMEN}

Se revisa teóricamente un conjunto de investigaciones recientes que se alinean con alguna de las cuatro grandes tradiciones en la sociología del espacio, tal como han sido propuestas por autores como Peter Saunders y Víctor Urrutia en la sociología urbana. Por una parte, se esclarecen sintéticamente las concepciones sociológicas del espacio que trascienden las propias temáticas «urbanas». Por otra parte, se examinan las áreas teóricas, las prioridades de análisis y los estilos interpretativos de las investigaciones empíricas clasificadas en cada corriente. Finalmente, se señala la poca atención que ha suscitado esa clasificación en cuanto a las posibilidades de complementariedad entre aspectos esenciales de cada corriente, a la vez que se defiende la relevancia transversal de la perspectiva conflictualista y holística en algunos estudios sobresalientes en cada una.

Palabras clave: Sociología del Espacio, Sociología Urbana, Teorías. 


\section{INTRODUCCIÓN}

Después de más de un siglo de estudios en la sociología urbana y rural, y después de tres décadas de renovación de esa tradición teórica y empírica, aún suscita perplejidad la referencia a una sociología del espacio en general. No obstante, más allá de las trincheras académicas, no es difícil percibir intereses comunes. El objeto de estudio de la sociología del espacio (a saber, los procesos y estructuras sociales en los que intervienen variables espaciales de forma destacada sobre otras coexistentes con ellas ${ }^{1}$ ) ha concitado la atención de numerosas ciencias sociales (antropología, geografía, economía, urbanismo, etc.), y del resultado de las diferentes combinaciones de enfoques podemos trazar, igualmente, un mapa de las diferentes sociologías del espacio disponibles. Éste será nuestro propósito aquí.

Para ello considero imprescindible un mínimo esfuerzo de codificación. Es decir, obligar a las teorías e investigaciones empíricas más relevantes a responder a las mismas preguntas: ¿Qué concepciones sociológicas del espacio se hallan en competencia? ¿Qué tipo de relaciones sociales se vinculan a los espacios? ¿Qué modelos de ciudad y de sociedad se encuentran en su trasfondo? Este ejercicio no será exclusivamente indicativo, pues exige selecciones previas y esclarecer nuestra posición teórica y epistemológica de partida. En particular, aquí nos apoyaremos en las corrientes conflictualistas y holistas de la sociología urbana (Alford y Friedland, 1985). Al menos, en el siguiente doble sentido: a) la sociología del espacio se preguntaría, sobre todo, por qué ocurren ciertos fenómenos socioespaciales percibidos como problemáticos, en qué circunstancias fueron posibles, cómo evolucionaron históricamente y qué importancia tienen en la reproducción de las estructuras sociales de desigualdad y dominación; b) en la tarea de descubrir relaciones causales no visibles cotidianamente o que contradicen el sentido común, estimamos más fructífero y orientador considerar como "espacios sociales» aquellos que resultan de procesos sociales de producción, de reproducción, de transformación, de apropiación, de uso, de gestión y de comunicación².

\footnotetext{
1 Según Leal, por ejemplo, una «sociología de los atributos espaciales» aludiría al estudio de «las connotaciones espaciales con las que son percibidas las entidades, tanto los individuos como los objetos o las agrupaciones y su interacción" (Leal, 1997). O, expresado más directamente, la sociología del espacio examinaría la dimensión espacial y los atributos espaciales de las relaciones sociales. De forma más clásica, en su reciente defensa de esta disciplina, Gans la ha definido como «el estudio acerca de cómo la sociedad -los individuos y las colectividades-transforma el espacio natural en social, cómo lo usan y lo intercambian, qué procesos y fuerzas sociales, económicas y otras intervienen en esos usos e intercambios, y cómo ambas clases de espacios afectan a los individuos, a las colectividades y a los procesos y fuerzas sociales» (Gans, 2002: 329). Ambas definiciones me parecen muy valiosas y oportunas con vistas a entender los fundamentos comunes de las sociologías urbana y rural sin caer en posiciones híbridas o insensiblemente aislacionistas.
}

2 Es decir, que los espacios funcionarían, a priori, como variables dependientes de algunos fenómenos sociales. O sea, como resultado o producto de acciones humanas. $\mathrm{O}$, en su defecto, como mediadores o como rasgos destacados de ellas. Los casos aparentemente inversos de «determinismo espacial», como aquellos en los que observamos que una cierta forma espa- 
Castells y Harvey, por ejemplo, formularon en su día, y casi a la par, algunos de los interrogantes clave de nuestro punto de partida: "¿Cuál es el proceso de producción social de las formas espaciales de una sociedad? y, recíprocamente, ¿cuáles son las relaciones entre el espacio construido y las transformaciones estructurales de una sociedad, en el seno de un conjunto internacional caracterizado por relaciones de dependencia?» (Castells, 1972: 27); “El problema de una nítida conceptualización del espacio se resuelve a través de la práctica humana con respecto a él. (...) La pregunta “¿qué es el espacio?” es, por consiguiente, sustituida por la pregunta "¿a qué se debe el hecho de que prácticas humanas diferentes creen y utilicen distintas conceptualizaciones del espacio?"» (Harvey, 1973: 6).

Buscaremos, por lo tanto, que esa perspectiva conflictualista y holista esté presente en alguna medida, de forma relevante y transversal, en las investigaciones empíricas recientes que seleccionaremos para caracterizar cada concepción sociológica del espacio. Esta selección es simplemente ilustrativa y, por lo tanto, no exhaustiva. Lo que se pretende demostrar es que desde la posición conflictualista-holista se pueden formular interrogantes empíricos procedentes de otras tradiciones teóricas sin merma del potencial explicativo de sus principios generales. Por consiguiente, sostendremos que existe un fondo de complementariedad entre esas tradiciones habitualmente poco reconocido. En todo caso, como estas páginas sólo aspiran a servir de síntesis y guía a otras obras teóricas, remitimos a ellas para profundizar en las más notorias incompatibilidades entre las distintas escuelas de sociología del espacio, o para debatir acerca de las contradicciones internas de cada una. Para ello procederemos a exponer una somera descripción de esas escuelas mencionando algunas de las investigaciones actuales que las mantienen vigentes. En concreto, aquí han sido agrupadas en cuatro grandes corrientes siguiendo la clasificación sugerida desde la sociología urbana por autores como Peter Saunders (1981), en el ámbito anglosajón, y Víctor Urrutia (1999), en el hispano3: ecología humana-urbana; cultura urbana; políticas urbanas; consumo colectivo. La tabla 1 (también retomando aportaciones de Dunleavy, 1980; Savage y Warde, 1993; LeGates y Stout, 1996) recoge sintéticamente (aún más que lo practicado en el texto) sus características principales.

cial — de una plaza o de un aula escolar, por ejemplo— favorece unas u otras relaciones sociales, se tomarían, en principio, como descripciones incompletas de los procesos sociales que han dado lugar a esos espacios o como una dimensión importante, aunque no determinante, de las relaciones sociales que tienen lugar en ellos. En este sentido estamos más próximos de los enfoques «socioespaciales» (Gottdiener y Hutchison, 2000) que de los «constructivistas» (Gieryn, 2002).

3 En la sociología rural, por ejemplo, es recomendable la clasificación entre modernización, marxismo agrario y neonarodnismo ecológico, de González y Sevilla (1993), para enmarcar los estudios sobre el desarrollo de las actividades agrícolas —incluyendo ahí desde las pesqueras, forestales y puramente extractivas hasta las del agroturismo- o las estrategias de acción colectiva de las poblaciones dedicadas a ellas o a conseguir el acceso a la tierra en usufructo. No obstante, continuaremos la exposición bajo el supuesto de una básica concomitancia y preocupación por la relevancia de las variables espaciales tanto en la sociología rural como en la urbana. 


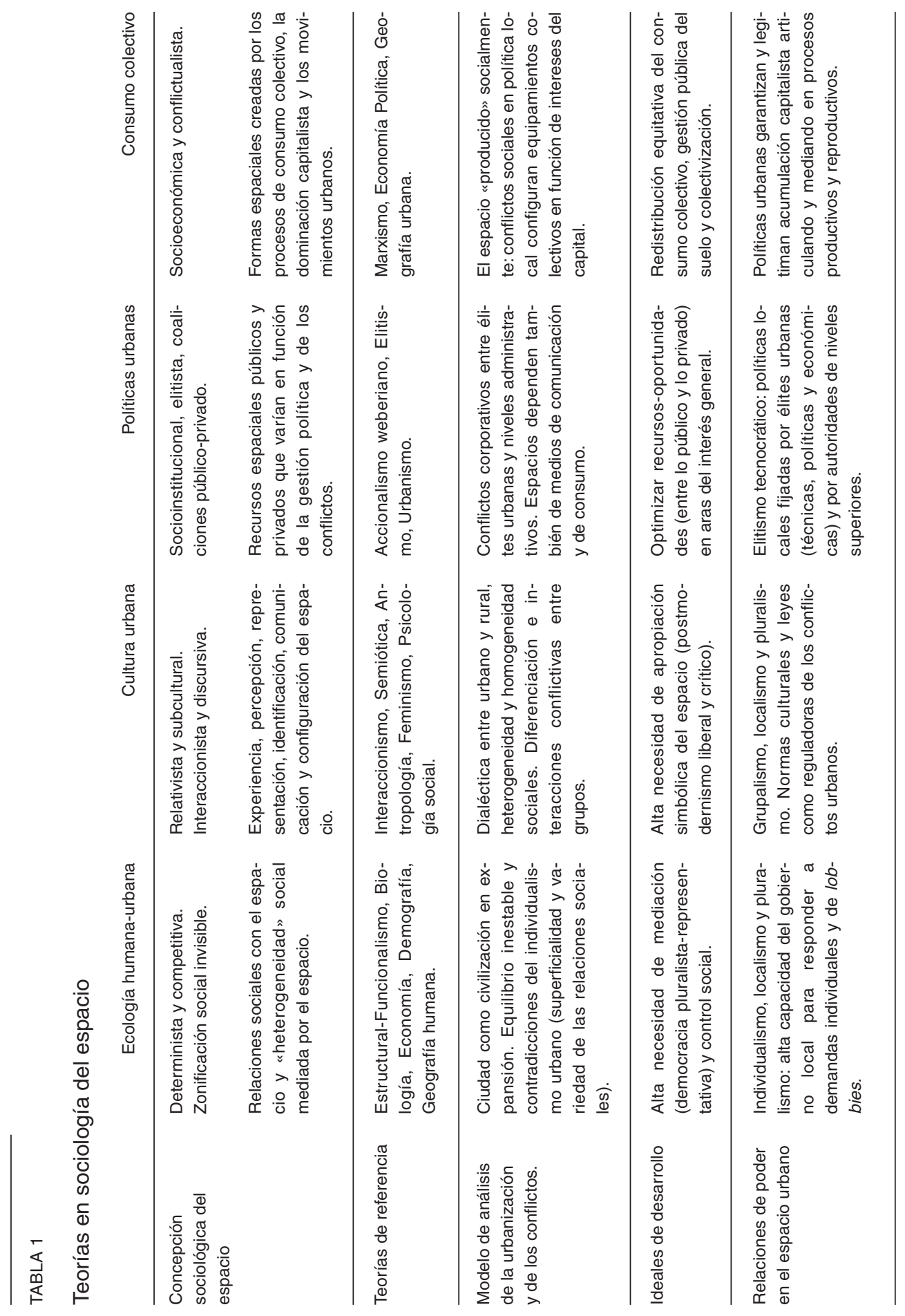




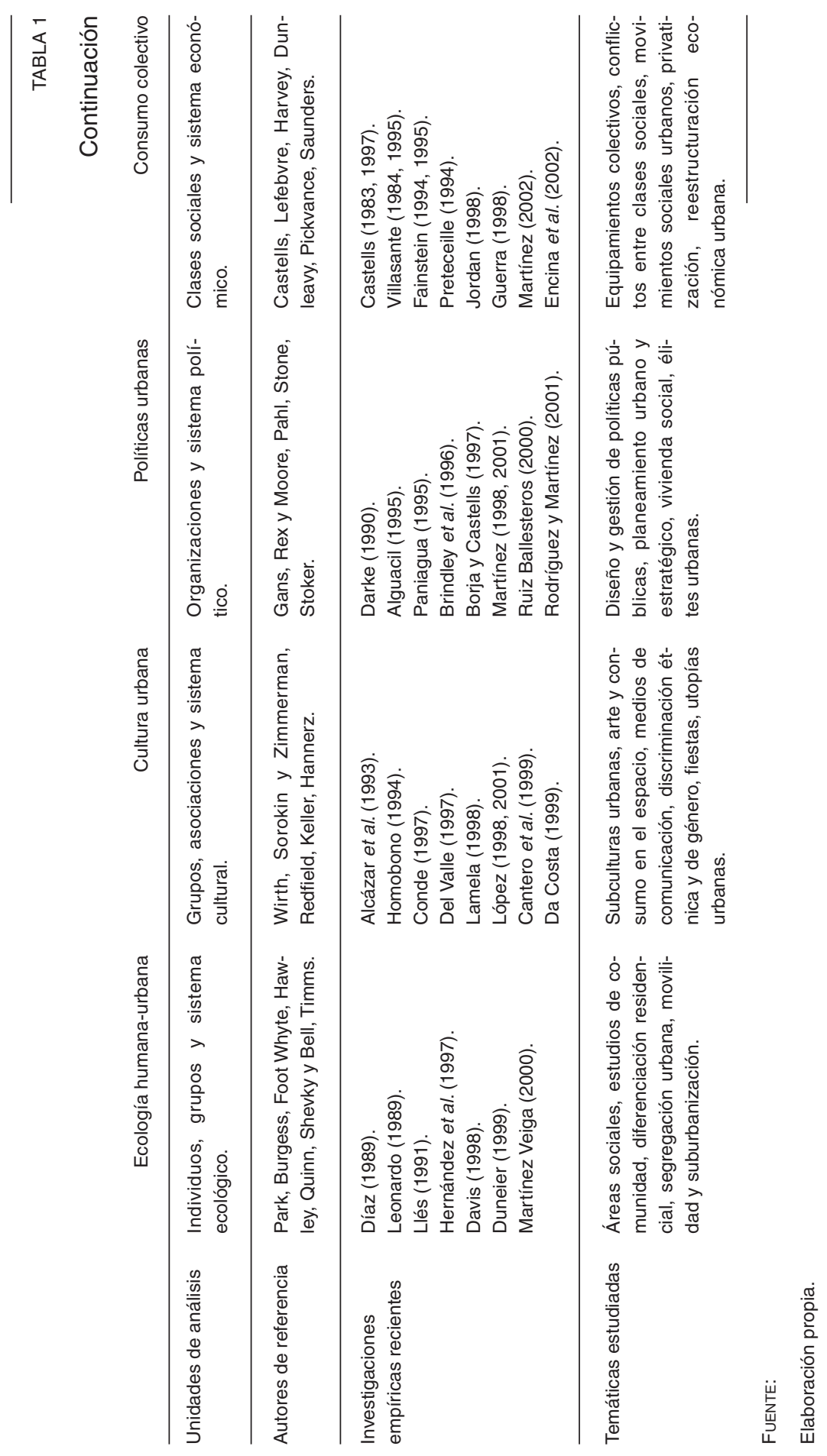




\section{ECOLOGÍA HUMANA-URBANA}

Bajo esta calificación se ha reunido a un conjunto de estudios urbanos que arrancan de la observación de áreas sociales en la ciudad de Chicago desde principios del siglo xx y que se extienden hasta los estudios «micro» de comunidades y los estudios «macro» de diferenciación residencial de las últimas décadas. En principio, se asientan en un planteamiento naturalista: explicar las pautas de regularidad en la ocupación del espacio por los diferentes grupos sociales ${ }^{4}$.

Ahora bien, ¿qué es el espacio, desde el punto de vista sociológico, para estos autores? Básicamente, podríamos contestar diciendo que el espacio (y, sobre todo, el espacio urbano) sería un bien escaso, necesario y deseable, por lo que estaría constantemente sometido a relaciones de competencia. No es difícil deducir, por lo tanto, que el espacio en particular o el medio ambiente en general jugarían un papel destacado en todas las relaciones sociales, según los postulados de esta escuela. Conviene puntualizar, en todo caso, que pocas veces llegaron a considerarlo como una causa absolutamente determinante de las relaciones sociales, aunque sí se consideraría como «marcado» por las características demográficas y por el tipo de organización social de sus habitantes y devolvería luego las marcas a esos y a otros nuevos moradores. De ahí que se haya tildado su concepción, omitiendo esos matices, como determinista.

En esta concepción sobresale con luz propia, a mi juicio, ya desde los textos pioneros (Park, 1925), un objetivo sociológico fundamental y encomiable consistente en comprender y delimitar las invisibles «regiones morales» (que también podríamos identificar como zonas, barrios, comunidades, etc.) en que se dividiría toda ciudad o asentamiento humano. Por una parte, esos «mapas sociales» se realizarían en función de las subculturas específicas (normas, costumbres, etc.) de los grupos sociales ocupantes, del valor económico del suelo y de pautas de localización física que replicarían esencialmente lo sucedido con las distribuciones espaciales de otros organismos no humanos (a saber, los recurrentes fenómenos de invasión, sucesión, comensalismo, simbiosis, etc.). Por otra parte, no es casual el adjetivo de «morales»: nos remite a la identificación durkheimiana entre las ciudades y una elevada densidad moral o heterogeneidad social, dentro de la cual se incitaba a descubrir las pautas normales de ocupación y convivencia, tanto como aquellas desviaciones y zonas fuera de la ley.

En definitiva, se trata de un enfoque que, desde el trasfondo cultural y económico señalado, se concentra en explicar el conjunto del sistema ecológico que constituyen los grupos

4 Uno de los más notables hagiógrafos de esta escuela sugirió incluso una interpretación más kantiana: «la principal contribución de la tradición de Chicago ha sido su preocupación por localizar los hechos sociales seriamente, por ver toda la vida social situada en el tiempo y en el espacio» (Abbott, 1999: 3). 
sociales al relacionarse con su medio y al trazar fronteras territoriales en el espacio. Como ha explicado Díez Nicolás (1984) al exponer las teorías de la segunda generación de ecólogos (Hawley, Quinn y Duncan), serían las cuestiones relativas al equilibrio, la competición, la expansión y la reproducción de las comunidades las que afectarían centralmente a los individuos y grupos que participan de esos sistemas ecológicos y las que, por lo tanto, deberíamos investigar sociológicamente ${ }^{5}$.

En gran medida, la crítica general a estas premisas está representada por las corrientes que veremos después. Lo que me interesa subrayar ahora es que algunas de las prioridades de análisis de la ecología humana-urbana aún no han perdido su vigencia: en especial, la descripción y el análisis de «áreas sociales». Ahora bien, de forma más específica: ¿qué variables se han seleccionado para trazar esas áreas?

En los estudios más clásicos sobre diferenciación residencial dentro de una misma ciudad se ha recurrido, sobre todo, a las variables tradicionales socioeconómicas, de composición familiar y de movilidad migratoria (Leonardo, 1989; Díaz, 1989). Algunos investigadores más afines a una posición conflictualista (por ejemplo, Llés, 1991) han sugerido añadir otras más acordes a espacios metropolitanos como las de «estilos de vida» (en el sentido de nuevas formas de consumo y de relación social) y la «movilidad social intergeneracional». Para la identificación de los barrios más vulnerables en distintas ciudades españolas, Hernández Aja y otros (1997) han propuesto fijarse en otras dimensiones más directamente espaciales, como la complejidad y variedad de funciones, la existencia y distancia a equipamientos públicos, y la identidad del barrio en el conjunto de la ciudad y para sus moradores. Además de la orientación más propiamente urbanística, estos últimos autores encontraban insuficiente los datos generales proporcionados por el Censo (sobre desempleo, nivel de estudios y problemas constructivos de las viviendas, fundamentalmente) para jerarquizar los mencionados barrios vulnerables.

En otros interesantes estudios de caso más cualitativos y micro (Martínez Veiga, 2000) se ha asociado la sucesión de distintos grupos étnicos en cada zona del barrio en función del tipo de mercados negros que se crearon, especializados en la transacción ilícita de vivien-

\footnotetext{
5 Se han subrayado también dos rasgos más para definir a esta corriente: a) la importación de conceptos propios de la ecología biológica tenía la virtud de abrir la sociología a concepciones espaciales de otras ciencias, pero esa importación condujo a posturas extremas que incluso pretendían convertir el modelo biológico en base «material» explicativa para toda la sociología (Urrutia, 1999: 12), o bien derivaron en la cosificación de conceptos que sociológicamente podían tener múltiples connotaciones; b) en esta teoría la vida urbana sería un sistema en «equilibrio inestable» donde entran en conflicto mundos de vida próximos y refractarios a la vez; cruces de culturas diferentes junto a la superficialidad y transitoriedad de las relaciones; racionalidad organizativa y mediación e impersonalidad (Park, 1925; Wirth, 1938). Sin embargo, como acertadamente han señalado algunos críticos, se presiente en el fondo de este modelo de análisis un alegato a favor del poder civilizador y homogeneizador de las ciudades modernas que, además, conllevaría la necesidad de aumentar el control social en ellas como antídoto a la intensa interdependencia y a las tendencias anómicas que también contendrían (Schwendinger y Schwendinger, 1974; Varela y Álvarez-Uría, 1989: 39-48; Davies y Herbert, 1993).
} 
das sociales o en el narcotráfico. Pero esa segregación socioespacial poseía también sólidos condicionamientos estructurales: la responsabilidad planificadora del Estado y las deficiencias constructivas provocadas por las empresas adjudicatarias de la edificación de viviendas de promoción pública. Por último, para el caso de la ciudad de Los Ángeles existe un estudio de «mapas sociales» realizado por Mike Davis (1998: 377), quien reconoce explícitamente la deuda con el «diagrama más famoso de las ciencias sociales», el de las cinco zonas concéntricas de Burgess. La originalidad de su contribución reside en que Davis introduce la incidencia de variables como el miedo, la violencia, los espacios del narcotráfico, la vigilancia policial de los espacios, los lugares de revueltas y los barrios bajo el control armado de distintas colectividades o bandas juveniles (véase la figura 1).

FIGURA 1

La ecología del miedo

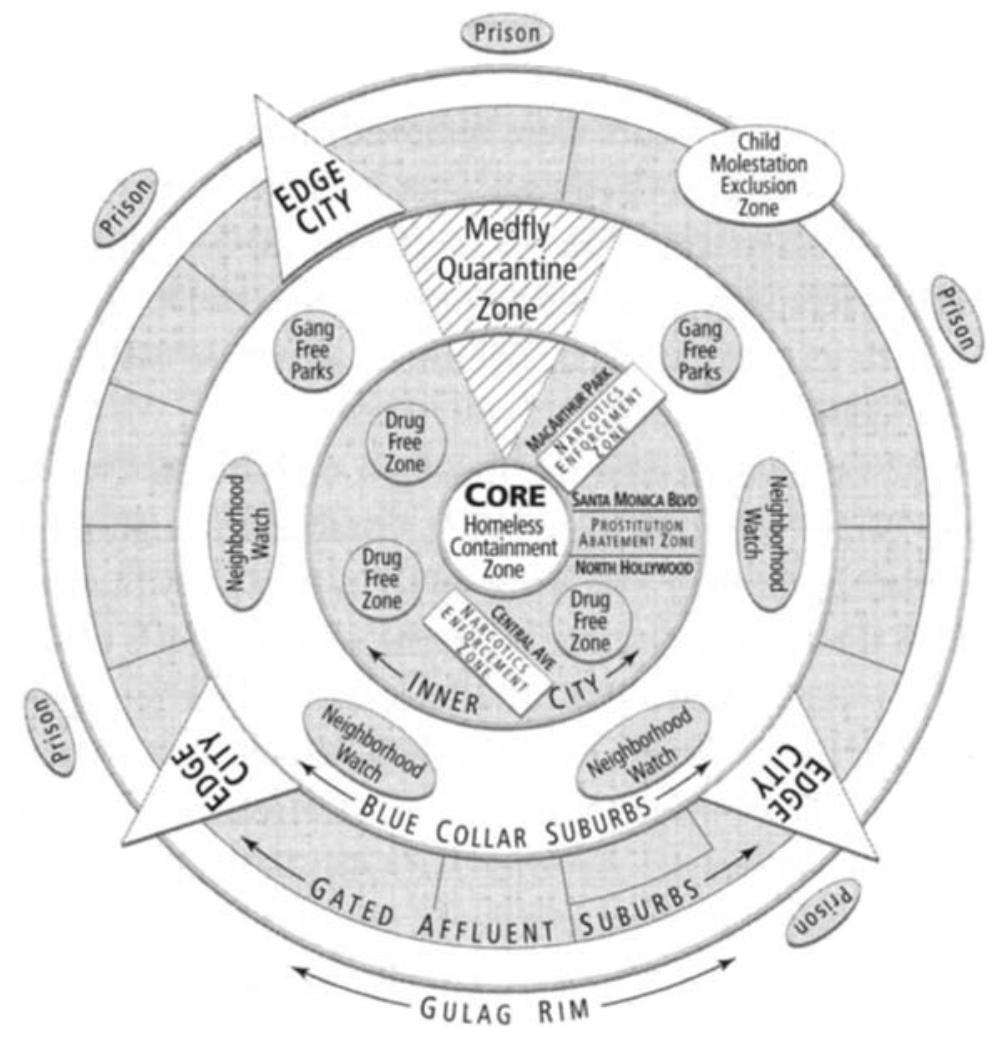

FUENTE:

Davis (1998: 365). 
En definitiva, ésta es una de las distintas posibilidades abiertas por todas esas investigaciones para mostrar la distribución espacial de los fenómenos sociales y, por lo tanto, de las desigualdades sociales según el tipo de variables que utilicemos. Otras veces se recurre a «manchas» sobre planos a escala y, casi siempre, se procura hacer visible en el espacio una jerarquía de ventajas y desventajas en la ocupación de las distintas zonas de la ciudad. Esa realidad socioespacial, por lo tanto, condiciona nuevos desplazamientos y elecciones de localización, aunque es evidente que no ha surgido de forma natural por simples determinaciones geográficas del lugar ni se trata de un simple reflejo de la distribución de la renta, tal como postularon algunos pioneros de la escuela de Chicago ${ }^{6}$.

\section{CULTURA URBANA}

La tradición de la cultura urbana se genera en íntima relación con la corriente teórica de la ecología humana-urbana. De hecho, es frecuente comprobar que autores de ambas corrientes asumen el postulado de Durkheim acerca de la alta heterogeneidad de las relaciones sociales en los espacios urbanos. Sin embargo, los representantes de la cultura urbana le conceden más importancia a la productividad cultural de los grupos sociales que a su distribución espacial. Es decir, destacarían más sus concepciones y formas de habitar los espacios que las características demográficas, naturales o urbanísticas de esos espacios.

En este sentido, podemos afirmar que ahora el espacio es concebido sociológicamente en tanto que espacio imaginado, planificado, objeto de la comunicación, soporte de símbolos, proyección de ideales, de formas de vida y de expresión cultural de toda índole. Los sujetos de esas concepciones serían, lógicamente, los múltiples grupos sociales que coexisten en el medio urbano y las representaciones colectivas y subculturas que crean y condicionan las ideas y conductas de sus miembros individuales. Por esta razón, a menudo esta sociología del espacio ha sido tildada de «relativista», ya que daría a entender que se generarían tantas ideas de espacio como grupos informales, asociaciones, comunidades, estilos de vida y formas de interacción existiesen. Una deriva epistemológica que no tenemos por qué aceptar ni superponer a toda interrogación acerca de cómo piensan los colectivos acerca de los espacios que habitan o en los que sueñan.

En todo caso, me parece conveniente recordar que ha sido precisamente desde esta corriente desde la cual se establecieron los primeros puntos de anclaje del debate entre lo ru-

\footnotetext{
6 Se podrían consultar también una serie de investigaciones acerca del impacto medioambiental de los asentamientos humanos, del acceso a los recursos naturales o de la dependencia alimentaria y energética de las ciudades, que han utilizado nociones como la de «ecosistema social», pero que rara vez han asumido de forma central las orientaciones sociológicas de esta escuela (Martínez Alier, 1993; Lemkow, 2002), por lo que las obviaremos aquí.
} 
ral y lo urbano. De hecho, destacarían sus concepciones originarias acerca del habitante urbano, construidas a menudo por oposición ideal a las características atribuidas al campesino. De este modo, autores como Simmel, Wirth, Sorokin, Zimmerman o Redfield entendieron la vida urbana caracterizada por elevados índices de asociacionismo, por una elevada movilidad social y residencial, y por ideales más progresistas e innovadores que los de los habitantes rurales (Camarero, 1993: 33-49; González y Sevilla, 1993: 28-33). Pero la realidad urbana contendría importantes contradicciones, ya que también promovería el individualismo competitivo, relaciones sociales superficiales, patologías psíquicas, el aumento de la delincuencia y la «oligarquización de la democracia» (Wirth, 1938).

La contraposición sociológica entre lo rural y lo urbano ha sido ampliamente cuestionada7, por lo que lo mejor, a nuestro juicio, de la escuela de la cultura urbana ha ido fijando su atención más en la comprensión de los discursos de cada grupo social al apropiarse y usar espacios determinados, y en visibilizar sus reglas culturales de interacción. En todo caso, aquella contraposición nunca ha sido descartada del todo porque nutre de un modelo ideal de vida urbana que se puede usar, al estilo de los tipos ideales weberianos, para contrastar los modelos utópicos y las formas híbridas que aparecen por doquier.

Cada vez más las investigaciones que siguieron esta senda tendieron a concentrarse en la descripción de los «mundos de vida», los discursos y las reglas culturales de interacción propios de los diversos grupos que coexisten en los espacios urbanizados y habitados. Ése sería el caso de un brillante estudio sobre los vendedores de libros usados y robados en las aceras en un barrio acomodado de Nueva York (Duneier, 1999). Muchos de sus protagonistas se encontraban atrapados en un círculo fatal de carencia de vivienda, precariedad laboral, dependencia asistencial y control social, pero el investigador puso especialmente de manifiesto la coexistencia de distintas clases sociales en un mismo barrio, la reflexividad de los actores (por ejemplo, al vender ellos mismos el libro que les analizaba y participar, incluso, en seminarios universitarios invitados por el sociólogo) y las múltiples instancias sociales implicadas en la reproducción y control social de ese pequeño mundo.

En esa misma línea existen varios estudios realizados sobre los espacios públicos de encuentro de personas homosexuales en los que se muestran, por ejemplo, formas muy poco

\footnotetext{
7 En las formulaciones originarias el campesinado, por ejemplo, aparecía ligado a valores tradicionales, conservadores, localistas, sin capacidad de ahorro, etc., desvalorizándose sus conocimientos, sus innovaciones tecnológicas, sus conflictos sociales por la tierra, los excedentes generados y sus visiones ecologistas de las relaciones socioespaciales (Sevilla y González, 1996). En el texto canónico de Wirth, por otra parte, todo parecía conducir al elogio de algunas virtudes de la homogeneidad rural y a infravalorar la creatividad, la libertad y las amplias oportunidades y estímulos proporcionados por la vida urbana, que, no obstante, Wirth también asumía como puntos de partida (Leal, 1988; Urrutia, 1999: 19). Al mismo tiempo, se idealizaría una vida rural sin conflictos y se concebiría una vida urbana sin «aldeas» interiores, barrios, vecindarios y grupos con ostensible estabilidad, homogeneidad y profundidad en sus relaciones (Keller, 1968; Hannerz, 1986; Savage y Warde, 1993: 99-110).
} 
visibles de apropiación de los aseos públicos en las estaciones de transporte y desarrollados códigos de comunicación no verbal practicados en distintos lugares (Guasch, 1991); o los frecuentes análisis sobre el graffiti (Sempere, 1977; Castleman, 1982; López, 1998) y sobre otras formas de expresión artística en la calle (Harrison-Pepper, 1990), destacando también las interacciones conflictivas con las autoridades y las pautas de organización informal, como demuestran los frustrados intentos de limpieza de los graffiti o su recuperación parcial hacia espacios formalizados de exposición (Castleman, 1982: 162).

Creo que es ilustrativo incluir en esta perspectiva las investigaciones de distintas autoras acerca de las concepciones espaciales según el género y acerca de los efectos socioespaciales de discriminación sufridos por las mujeres. Teresa del Valle pone de relieve que las mujeres conciben los espacios públicos como espacios en los que se ha traspasado un límite o como espacios de paso. Eso se manifestaría, por ejemplo, en sus recorridos diferenciales con respecto a los masculinos y marcados constantemente por las necesidades domésticas (Del Valle, 1997). Ángela López, en la ciudad de Zaragoza, constata que muchas mujeres se sienten inseguras en los espacios vacíos, en garajes, en taxis y, durante la noche, en espacios connotadamente masculinos como los bares. $Y$ esa percepción tiene su correlato en las percepciones de muchos hombres relativas a que en esos espacios y momentos pueden agredir más impunemente a las mujeres (López, 2001).

Frente a las reivindicaciones feministas tradicionales para que las mujeres se incorporasen activamente al espacio público y abandonasen el hogar que se identificaba con una «prisión», recientemente, Jane Darke comprobó que las identificaciones de las mujeres con el espacio doméstico son esencialmente ambivalentes. Es decir, que la vivienda puede provocar aislamiento social, a la vez que muchas mujeres la aprecian como el espacio que mejor satisface su necesidad de intimidad. Al mismo tiempo, las mujeres siguen experimentando la presión social de las altas expectativas que generan al ser consideradas como las exclusivas responsables de la gestión del hogar, pero es también frecuente que se sientan gratificadas por el reconocimiento social de sus habilidades y capacidades de organización doméstica y cuidado personal (Darke, 1998: 78).

Un último conjunto de estudios lo constituirían aquellos que examinan las formas de apropiación espacial por parte de los jóvenes y aquellos que se dedican a interpretar las distintas valoraciones del espacio construido y de las actuaciones urbanísticas que tienen las poblaciones en función de su clase social o lugar de residencia. Si atendemos a criterios de edad, disponemos de varios análisis de las «cuadrillas juveniles» en el País Vasco que coexisten con otros agrupamientos (como pandillas y tribus urbanas) y que se apropian con sus distintivos estilos y actitudes de espacios diferenciales de la ciudad, especialmente en lo que atañe a su diversión (bares, espacios abiertos y discotecas, por ejemplo) (Al- 
cázar et al., 1993; Homobono, 1994). Y si atendemos a agregados familiares y socioeconómicos en cuanto a sus valoraciones de los espacios y problemas urbanos más acuciantes, disponemos, por ejemplo, de un completo estudio del conjunto de la ciudad de Granada (Conde, 1997), otro sobre Lugo (Lamela, 1998) y dos sobre los centros históricos de SeviIla (Cantero et al., 1999) y Lisboa (Da Costa, 1999), sin que se descuide excesivamente el reconocimiento de las desigualdades y conflictos sociales asociados a cada espacio bajo observación.

La dimensión cultural de los espacios y la atención hacia los «lugares significativos» y los espacios de la vida cotidiana han sido consideradas también por autores marxistas, como Henri Lefebvre y David Harvey, en íntima articulación con las dimensiones económicas y políticas de la producción social del espacio, pero eliminando su conceptualización como simple excrecencia ideológica o superestructural que se estipulaba en las versiones más tradicionales del marxismo (Harvey, 1987; Urrutia, 1999: 20) ${ }^{8}$. De acuerdo con eso, me resulta de especial interés para diseñar investigaciones empíricas concretas la parrilla de «prácticas espaciales» elaborada por Harvey (1987: 368). En ella cruza variables relativas a procesos económicos («experiencia») y comunicativos («percepción» y «representación») con otras muy semejantes a las enunciadas desde el llamado «urbanismo normativo» (Lynch, 1981): acceso, uso y control. Sin poder detenerme ahora en todas sus anotaciones, sólo quiero resaltar que en esa clasificación no resulta evidente cómo se incluirían las problemáticas étnicas, de género o las relativas a las ideologías en el urbanismo (Scott, 1998) (ver tabla 2).

\footnotetext{
8 Conviene recordar en este punto que, inicialmente, Castells (1972: 95-117) tildó de «ideología urbana» las contribuciones que van desde Simmel y Wirth hasta Lefebvre, aunque él mismo reconocía años después la central dimensión identitaria de los movimientos sociales urbanos al entrar en un conflicto de «significados urbanos» (Castells, 1983: 406-409) y al buscar una «identidad cultural», comunicativa, local e independiente de los medios de comunicación de masas (Castells, 1983: 430-431). Véanse también, a este respecto, Villasante (1984) y Martínez (2003).
} 
TABLA 2

Prácticas espaciales socioculturales

Accesibilidad

a distancia
Apropiación y uso

del espacio
Dominación y control del espacio

\begin{abstract}
Prácticas espaciales materiales (experiencia)
\end{abstract}

Entornos urbanos edificados, espacios sociales de la ciudad y otras zonas verdes; redes sociales de comunicación y ayuda mutua
Propiedad privada del suelo, divisiones estatales y administrativas del espacio; vecindarios y comunidades excluyentes; zonificación segregadora y otras formas de control social (vigilancia y policía)
Representaciones del espacio (percepción)
Medidas sociopsicológicas y físicas de la distancia; elaboración de mapas; teorías de la «fricción de distancia» (principio del mínimo esfuerzo, física social, rango de un bien, lugar central y otras formas de teoría de la localización)
Espacio personal; mapas mentales del espacio ocupado; jerarquías espaciales; representaciones simbólicas de los espacios
Espacios prohibidos, «imperativos territoriales»; comunidad; cultura regional; nacionalismo; geopolítica; jerarquías
«Los medios son el mensa-
Espectáculos populares;
Espectáculos organizados; je»; nuevos modelos de transacción espacial (radio, TV, cine, fotografía, pintura, manifestaciones en la calle, disturbios; lugares de es- monumentalidad y espacios construidos ritualmente; ba- pectáculos populares (ca- etc.); difusión del «gusto» lles, plazas, mercados); ico- nografía y graffiti de los símbolos del capital

FUENTE:

Harvey (1987: 368)

\section{POLÍTICAS URBANAS}

Desde la década de 1960 comienzan a desarrollarse nuevos enfoques en la sociología urbana que optan por análisis macrosociológicos y que encuentran fundamentación en orientaciones teóricas weberianas (sobre la racionalización burocrática y la estratificación de acuerdo a oportunidades de mercado) y elitistas (sobre la reproducción de las minorías dominantes). ¿Qué significa ahora, sociológicamente, el espacio? En primer lugar, el espacio es considerado aquí como un recurso económico codiciado; concepción que, en el fondo, compartían con los ecólogos humanos. Pero, a diferencia de ellos, ahora ese recurso será concebido como resultado -no natural — de procesos políticos de ordenación y gestión del espacio. Rex, Moore, Pahl y otros pioneros de la corriente de las políticas urbanas conside- 
raban, además, que sólo ciertos grupos sociales dentro de las organizaciones que intervienen en el sistema político o en el mercado controlarían dichos procesos, gracias a sus posiciones sociales privilegiadas según sus atributos económicos, informativos o institucionales. A ese grupo se le conocerá habitualmente como urban managers o «élites urbanas».

Víctor Urrutia ha distinguido tres ideas rectoras en esta corriente teórica (Urrutia, 1999: 22): 1) las desigualdades sociales de recursos en general tendrían siempre una manifestación espacial; 2) el espacio reflejaría las desigualdades sociales, pero no lo haría mecánicamente, sino a través de la mediación de los sistemas burocráticos y de las acciones e ideas de las élites urbanas; 3 ) en toda sociedad se producirán conflictos, alianzas y negociaciones entre los grupos de poder para ejercer influencia en los procesos de planificación urbana. Las élites urbanas, en definitiva, comprenderían a personal técnico, gobernantes, gestores, inversores, empresarios, partidos políticos, medios de comunicación, etc. Los conflictos, en consecuencia, se podrían establecer: $\left.1 .^{\circ}\right)$ entre esas élites urbanas locales; $2 .^{\circ}$ ) entre ellas y los niveles supralocales del Estado; y $3^{\circ}{ }^{\circ}$ ) entre las élites y las organizaciones ciudadanas y sociales en general. De hecho, esas élites tendrían también sus propias agendas de prioridades y utilizarían mecanismos que pueden burlar la ley en aras de defender más eficientemente sus intereses corporativos y asegurar sus ganancias privadas (intercambios de favores, tráfico de información privilegiada, presión sobre los planificadores, financiación de campañas políticas, etc.) (Pickvance, 1984).

Por lo tanto, esos conflictos multilaterales inclinan la asignación de bienes urbanos a favor de uno u otro grupo social, a menudo con independencia del origen socioeconómico de éste debido a que en el proceso se pueden introducir otros factores de desigualdad social (por edad, género, etnia, adscripción ideológica o política, acceso a la información, etc.) (Dunleavy, 1980: 39-40). De todo ello se deriva una contribución importante con respecto a las teorías de la ecología humana y de la cultura urbana. En estas últimas, de forma poco realista a nuestro juicio, predominarían más los conflictos sociales y culturales de la vida urbana configurando «áreas invisibles» que los propiamente institucionales o políticos; se le atribuiría una alta autonomía a la política local; y se asumiría una visión pluralista de las relaciones de poder local, por la cual existirían buenos cauces informativos para que la ciudadanía expresase sus demandas y ejerciese influencias en sus gobernantes, lo cual se debería demostrar en las decisiones efectivamente tomadas por éstos ${ }^{9}$.

\footnotetext{
9 No podemos obviar que al «elitismo urbano» también se le ha achacado a menudo que las élites del sector público y del privado no actúan con base a los mismos parámetros, que no siempre son tan autónomas de las organizaciones e instituciones a las que están adscritas, que cada caso exige analizar los criterios usados por cada grupo de poder y sus coaliciones coyunturales, para finalizar polemizando con la misma condición «escasa» del espacio, posiblemente más un producto de los procesos económicos y políticos globales (no sólo los dominados por las élites locales) que un condicionamiento a priori de la desigualdad socioespacial (Saunders, 1981; Pickvance, 1984).
} 
En las últimas décadas, autores como Gary Stoker han estudiado nuevas redes de relaciones sociales que coaligan intereses de organizaciones públicas, privadas y sociales. Es el caso, por ejemplo, de Consejos Sociales y Sectoriales, de Fundaciones y Empresas Mixtas, que reúnen a las Administraciones Públicas, a empresas y a entidades sindicales o sociales de distinta índole. Estas coaliciones se basarían en la confianza, la cooperación y la reciprocidad más que en la organización jerárquica de la autoridad y en las agendas ocultas promovidas por grupos de presión, tal como se derivaba, en cambio, del enfoque elitista clásico (Stoker, 1995). Desde este planteamiento teórico, el principal objeto de estudio sociológico lo constituirían esas coaliciones o «regímenes» de gobernabilidad urbana, y las modalidades de compromiso y mutua adaptación de sus integrantes para promover la transformación de áreas degradadas, la aprobación de planeamientos urbanísticos o la realización de infraestructuras específicas (una aplicación empírica a la ciudad de Jerez de la Frontera puede verse en Ruiz, 2000).

La intervención pública como promotora de amplias coaliciones entre entidades públicas y privadas, por medio de procesos de planificación estratégica y del impulso de grandes proyectos urbanos terciarizadores, ha sido descrita prolíficamente en ciudades como Bilbao y Medellín (Colombia) (Rodríguez y Martínez, 2001; Martínez, 1998) ${ }^{10}$. Dentro de los estudios de remodelación de centros urbanos e históricos (Martínez, 2001), un caso de especial interés, a mi juicio, lo constituye un estudio de Roy Darke en la ciudad inglesa de Sheffield. Ese investigador destaca el papel relevante que jugaron los responsables técnicos del proceso al promover iniciativas de desarrollo socioeconómico al mismo tiempo que metodologías de planeamiento participativo. De un modo bastante innovador en comparación con otros procesos de planeamiento urbano, en este caso se dio audiencia a los múltiples grupos sociales que se identificaron como afectados ante las actuaciones previstas. En particular, reunieron grupos específicos de trabajo y discusión con mujeres, familias con niños pequeños, ancianos, personas con discapacidades, población desempleada, comunidades asiáticas y afrocaribeñas, jóvenes y organizaciones de trabajadores precarios. Todos esos grupos de trabajo siguieron procesos muy informales de relación y discusión, pero las necesidades e ideas que expresaron fueron muy influyentes en la nueva ordenación del centro urbano (Darke, 1990).

Un examen del planeamiento urbano en Inglaterra durante la década de 1980 identificó seis tipos ideales de «estilos de planeamiento» al cruzar la variable de «actitud hacia el mercado» con la de «naturaleza percibida de los problemas urbanos», tal como podemos apreciar en la tabla 3 (Brindley et al., 1996). A continuación exponían casos empíricos de

10 Una presentación amplia de numerosos casos internacionales de planificación estratégica y la descripción general de sus premisas puede verse en Borja y Castells (1997). 
TABLA 3

Estilos de planeamiento urbano

Actitud hacia los procesos de mercado

Percepción de la naturaleza de los problemas urbanos
Críticos con el mercado: reequilibrio de desigualdades creadas por el mercado
Dirigidos por el mercado: corrección de ineficiencias y apoyo a procesos de mercado
Áreas boyantes: problemas menores y mercado boyante
Planeamiento regulador (jerarquía de competencias planificadoras, regula usos del suelo y disciplina urbanística)
Planeamiento tendencial (facilita demandas de promotores y constructores inmobiliarios y de industrias hegemónicas, reducción de controles y procedimientos)
Áreas marginales: bolsas de problemas urbanos e interés potencial para el mercado
Planeamiento popular (participación pública, diseño e implementación de planes por las comunidades locales)
Planeamiento promotor (proporcionar infraestructuras públicas y urbanización para estimular localización e inversiones privadas, zonas con exenciones fiscales y subsidios a empresas)

Planeamiento con inversión privada (métodos empresariales y agencias privadas de gestión, privatización de servicios sociales)
Áreas abandonadas: problemas urbanos integrales y mercado deprimido
Planeamiento con inversión pública (adquisición pública de suelo, promoción de vivienda social, creación de «Nuevas Ciudades», desarrollo integral y coordinación interinstitucional)

FUENTE:

Brindley et al. (1996: 9-25).

ciudades que se correspondían con cada estilo de planeamiento, demostrando que esa nueva situación de fragmentación del planeamiento se consolidó localmente con gobiernos estatales conservadores, en lugar de generarse una desaparición brusca del planeamiento tal como podría desprenderse de las políticas desreguladoras promovidas desde las instancias centrales.

La promoción pública de viviendas y, especialmente, la remodelación de barrios en la periferia de Madrid han sido evaluadas sociológicamente por varias investigaciones fácilmente enmarcables en esta corriente y en clara convergencia con una visión más conflictualistaholista. Entre ellas, cabría destacar conclusiones como las siguientes (Alguacil, 1995): 1) la elevada conflictividad interna y externa de los nuevos barrios de realojamiento, debido a las diferencias organizativas de las comunidades o a las divisiones étnicas; 2) la desaparición de espacios públicos que eran escenarios de una intensa vida comunitaria en los precedentes barrios de autoconstrucción; 3) la fractura social que produjeron los criterios buro- 
cráticos de adjudicación al no tener en cuenta las relaciones previas de vecindad y solidaridad (lo que no ocurrió en los modelos cooperativos de autopromoción); 4) el predominio de la propiedad como régimen de tenencia de las nuevas viviendas (por delante del alquiler) dio lugar a que se efectuasen numerosas reventas y traspasos ilícitos, por una parte, y exigió unos esfuerzos económicos privados muy altos para las unidades familiares realojadas (ver también Villasante et al., 1989; Paniagua, 1995).

\section{CONSUMO COLECTIVO}

Las distintas corrientes marxistas dedicadas a la sociología del espacio se han agrupado, en general, bajo el rótulo de «consumo colectivo». Esta denominación es debida a la línea teórica que inauguró Manuel Castells en la década de 1970 atribuyéndoles centralidad analítica a los «procesos de consumo colectivo» (o, expresados con la terminología marxista clásica, «procesos de reproducción de la fuerza de trabajo»). Tanto para ese autor como para otros afines, se trataría de analizar relaciones sociales esencialmente conflictivas cuya fuente directa de conflicto se halla en los procesos económicos globales de tipo capitalista (en los que el Estado interviene, a la vez, de forma decisiva). Es decir, que los problemas socioespaciales del consumo colectivo serían indisociables del conflicto entre el capital y el trabajo.

Por lo tanto, a la pregunta «¿qué es el espacio?», desde esta corriente se respondería diciendo que es una de las dimensiones de la «lucha de clases», del conflicto entre proletariado y burguesía. Para el primer Castells, lo más propiamente urbano de esa lucha de clases sería la demanda, la planificación, el acceso y la gestión de los «equipamientos colectivos". Se centra, por lo tanto, en los medios que sirven para que la clase trabajadora pueda satisfacer aquellas necesidades básicas que no satisface a través de su salario. De este modo, la acción estatal de índole redistributiva pasa a ser uno de los objetos centrales de los estudios del consumo colectivo.

Tal como puede observarse en la figura 2, el espacio es ahora, fundamentalmente, un producto social. Al menos los espacios que nos interesan a las ciencias sociales. Más precisamente, el espacio sería, en primer término, un resultado material de procesos productivos como los de urbanización y construcción; pero también, en un segundo término, el espacio sería resultado de procesos sociales de apropiación —en tanto que materia prima utilizable en la producción de mercancías o servicios, o en tanto que territorio donde se establece una propiedad privada o colectiva- En ese sentido, tanto el espacio físico, en general, como las formas espaciales resultantes de la intervención humana, en particular, serían de interés sociológico, pero siempre como producto de tres procesos socioeconómicos princi- 
FIGURA 2

Modelo neomarxista de análisis socioespacial

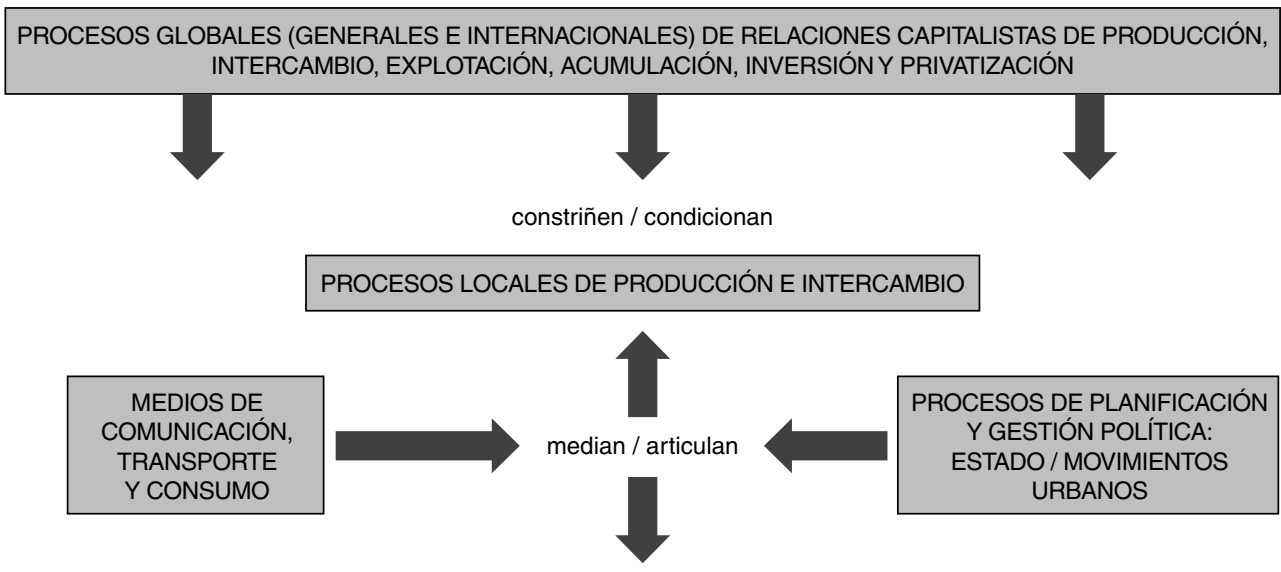

PROCESOS LOCALES DE REPRODUCCIÓN / CONSUMO COLECTIVO

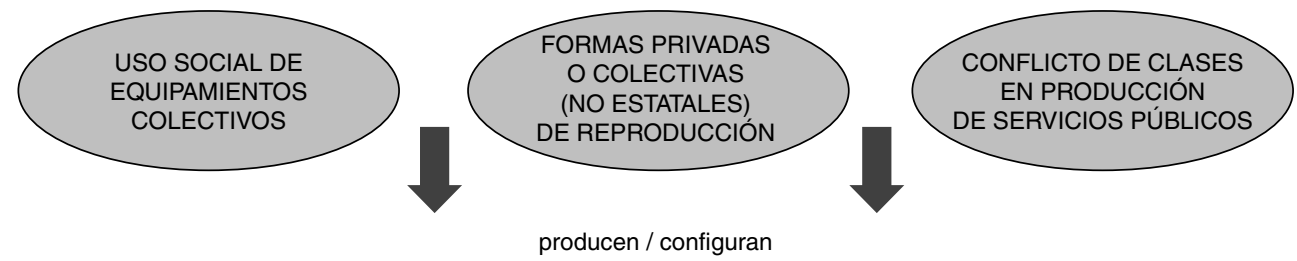

RELACIONES SOCIALES CON EL ESPACIO

FORMAS ESPACIALES

\section{FUENTE:}

Elaboración propia basada, fundamentalmente, en Castells (1972).

pales (los de producción, intercambio y reproducción) y de uno sociopolítico «articulador» de los tres anteriores (las políticas urbanas). Se puede apreciar, en todo caso, la centralidad de los procesos reproductivos en tanto que, de acuerdo con Castells, serían los que más nítidamente manifestarían en el espacio las relaciones sociales de desigualdad y de conflicto entre clases. Constituye, como se puede deducir, la principal fuente -aunque no la única- de la perspectiva conflictualista y holista que guía nuestra revisión teórica.

En coherencia con las anteriores premisas, las investigaciones disponibles han abarcado desde el estudio crítico de las variadas taxonomías elaboradas para comprender los equi- 
pamientos colectivos (Leal y Cortés, 1995; Hernández Aja et al., 2000), pasando por el problema de la vivienda en sus manifestaciones más crudas en cuanto a condensación de desigualdades sociales (como la exclusión residencial de la población «sin techo» o las dificultades de acceso a la primera vivienda para los jóvenes trabajadores en desempleo o con empleos inestables y temporales: ver, por ejemplo, en el ámbito anglosajón, Roberts, 1991; Forrest, 1991; en distintos tipos de asentamientos de Lisboa, Guerra, 1998; o un análisis general para ciudades occidentales industrializadas, Mingione, 1994), hasta desembocar en la comprensión de los cambios espaciales que se han producido en las grandes ciudades del mundo durante las tres pasadas décadas, con fuertes impactos espaciales de los procesos de desindustrialización, reestructuración económica, privatización de servicios públicos y de alta movilidad de capitales, personas e información (Preteceille, 1994; Harvey, 1996; una comparación reciente entre lo acontecido en Londres y en Nueva York puede verse en Fainstein, 1994; los trabajos de Saskia Sassen durante la última década —por ejemplo, Sassen, 1991, 1998— han supuesto una importante inflexión en los análisis socioespaciales, añadiendo la capacidad de atracción migratoria de las grandes metrópolis provocada por los flujos globales de capital).

No obstante, en el fondo de este esquema de análisis tan bien tramado, aparentemente, quedaron diversas cuestiones críticas pendientes: si las actividades productivas precisan algún espacio donde localizarse, ¿las decisiones empresariales a este respecto no alterarán, acaso, tanto la correlación de fuerzas entre clases como las políticas públicas?; ¿se disolvería definitivamente la distinción entre espacios rurales y urbanos debido a que el consumo colectivo se produciría en todo tipo de espacios?; ¿cómo distinguir el carácter espacial o urbano de la intervención del Estado si siempre actúa simultáneamente en ámbitos productivos y reproductivos? En ese sentido, tal como hemos intentado reflejar en la figura 2, otras contribuciones neomarxistas destacaron que en la producción de servicios (en el ámbito reproductivo) también existen conflictos de clase internos equiparables a los conflictos laborales en cualquier otro centro de trabajo. Por otra parte, no se debería desligar el examen de los servicios proporcionados por el Estado de los satisfechos al margen de él, de forma estrictamente privada o colectiva, en los hogares o en los barrios. Por último, en las etapas actuales del capitalismo, en las que se agudizarían las tendencias monopolistas y financieras, también habría que considerar, según Lojkine (1977), todos los procesos de comunicación y de legislación que articulan los procesos productivos y reproductivos con notables consecuencias en la configuración de los espacios de acuerdo a los nuevos intereses del capital (ver, de nuevo, Sassen, 1991). Todo lo cual nos aconsejaría atender tanto a las dimensiones materiales (medios de transporte, tecnologías de telecomunicación, gestión de la salud corporal, etc.) como simbólicas (educación, cultura, información, legislación, legitimación ideológica, etc.) de los espacios implicados en los procesos reproductivos. 
El otro eje del análisis neomarxista residía en la dimensión espacial de los conflictos entre clases; es decir, en el estudio de los «movimientos sociales urbanos». Este tipo de investigaciones se podrían diferenciar del enfoque de las «políticas urbanas» en que ahora se enfatizaría la base socioeconómica de los movimientos y su oposición a las políticas públicas, más que sus formas organizativas y la negociación. En gran medida, por lo tanto, Castells los consideraba una prolongación de la lucha de clases. Además, en coherencia con el planteamiento teórico que hemos visto, la reivindicación de mejoras en los equipamientos públicos y la preocupación por la planificación urbana subrayarían la dimensión espacial y urbana de estos movimientos sociales (Martínez, 2003). Pero las diferencias entre ambas corrientes no eran excesivas en este punto y, como han notado algunos autores, es necesario estudiar los «movimientos urbanos» también desde el punto de vista de sus contextos, recursos y dinámicas de movilización (Pickvance, 2003).

El estudio empírico más influyente de Castells sobre los movimientos urbanos comparando casos de distintos países ( $y$, en particular, las ciudades de Madrid, París y San Francisco) concluía distinguiendo tres dimensiones estructurales de esos movimientos: 1) la ya mencionada orientación hacia el consumo colectivo; y otras dos novedosas, 2) la organización asociativa y cultural de la vida comunitaria; y 3) la búsqueda de la descentralización política y la autogestión barrial (Castells, 1983: 430-431). Además, reconocía que su base podía ser interclasista, que podían distinguirse de las luchas de clases (sindicales) y de otros movimientos sociales (ecologismo, feminismo, étnicos, etc.), y que operaban más en un sentido «reactivo» - integrando la protesta, la participación y las demandas de reformas a las autoridades locales - que como materialización de un potencial revolucionario frente al capitalismo global (Castells, 1983: 444; para una crítica: Pickvance, 1985, 1986).

Otros estudios sobre el movimiento ciudadano en Madrid y sobre otros movimientos urbanos en Latinoamérica han subrayado más sus estructuras internas conformadas por redes sociales entre los colectivos y organizaciones implicadas y por sus distintos estilos de intervención, además de coincidir con Castells en la mediación clave que jugaron los medios de comunicación y los activistas o colaboradores con una formación técnica (Villasante, 1984, 1995). Desde la década de 1970, la atención concitada por los movimientos urbanos ha ido sacando a la luz un vasto y heterogéneo conjunto de fenómenos con frecuencia resistentes a la aplicación de los esquemas generales elaborados por Castells. Fainstein y Hirst (1995), por ejemplo, concluyeron que los movimientos urbanos no suelen establecer coaliciones duraderas con otros colectivos, organizaciones o partidos políticos, y que poseen una muy diversa composición social, oscilando desde la proclividad a ser protagonizados por las clases medias hasta los que son étnicamente homogéneos o los que se identifican con una causa o problema urbano específico. 
Como señala el propio Castells en una de sus últimas obras, es evidente que se ha experimentado una considerable mutación en cuanto a los más recientes movimientos urbanos y han cobrado visibilidad aquellos de carácter más reactivo y con menos potencialidades de cambio social (los ambientalistas de carácter localista y socialmente excluyentes tipo NIMBY, «no en mi patio trasero»; los que procuran suplir con «Estados del bienestar» alternativos la supervivencia en barrios pobres de grandes metrópolis; o el control espacial y económico de barrios urbanos por bandas juveniles o delincuenciales) (Castells, 1997: 8388). Pero, al mismo tiempo, las investigaciones recientes en esta perspectiva se han concentrado en la persistencia de movimientos «proactivos» acerca de la integración comunitaria (Marchioni, 1994; Alguacil, 1998) y en la emergencia de otros más novedosos en cuanto a sus objetos y medios de intervención espacial, dedicados a la reivindicación de los espacios urbanos para peatones y bicicletas (Jordan, 1998), a la reapropiación de edificios abandonados (Martínez, 2002; Pruijt, 2003), a campañas de ecología urbana por el ahorro energético y de agua (Tello, 1996), a la cultura popular de calle o la participación ciudadana en la elaboración de los presupuestos municipales (tanto de ciudades como de municipios rurales: ver, por ejemplo, Encina et al., 2002).

\section{CONCLUSIONES}

En las páginas anteriores se ha mostrado una rápida y necesariamente sintética visión acerca de las que podrían considerarse las cuatro principales corrientes de sociología del espacio. El objetivo del artículo era el de poner de relieve que algunos aspectos importantes de sus concepciones del espacio son claramente compatibles y deberían dar lugar a una teorización más amplia que atendiese a la complementariedad de las dimensiones espaciales de los procesos sociales y de los interrogantes empíricos sobre ellas. En todo caso, se ha defendido que esas virtudes se alcanzarían mejor poniendo siempre de relieve las distintas maneras por las que el espacio interviene en generar o reproducir desigualdades sociales. $\mathrm{O}$, desde otro ángulo de la misma posición conflictualista y holista, tratando de responder a la pregunta siguiente: ¿qué procesos, estructuras y prácticas sociales producen una u otra forma espacial?

El espacio se puede concebir sociológicamente, según cada una de las corrientes expuestas y sin entrar ahora en todos sus matices, como: 1) un mosaico de áreas sociales asociadas a grupos determinados y a prácticas regulares; 2) un objeto de comunicación, planificación y proyección de vivencias; 3 ) un recurso singular que se organiza de acuerdo a los intereses y acciones de las élites económicas y políticas; 4) una dimensión suplementaria de los conflictos globales entre capital y trabajo. Cada una de esas concepciones se acompaña de otras premisas, implicaciones y precauciones críticas que han orientado fructífera- 
mente numerosas investigaciones empíricas en las últimas décadas. No obstante, nuestro propósito aquí ha sido el de seleccionar algunas que han estado impregnadas profundamente por las preocupaciones derivadas de las dos últimas concepciones, a la vez que ofreciendo respuestas a los interrogantes típicos de las otras perspectivas.

Hasta ahora, en un intento semejante por buscar una superación de los puntos muertos a los que ha llegado cada corriente, a la vez que sacándole partido a sus hallazgos y contribuciones más valiosas en complementariedad entre enfoques teóricos, podríamos citar los intentos de Amos $\mathrm{H}$. Hawley por encontrar conceptos de convergencia entre el marxismo y la ecología urbana, seguidos después por autores como David Harvey (1996) al señalar que toda «ecología social» comprendería procesos de competición, cooperación, adaptación y transformaciones ambientales (sobre la noción de «ecología social», véase también, por ejemplo, Bookchin, 1991). Harvey, además, coincide con otros sociólogos como Giddens y Castells en la propuesta de no desligar las formas espaciales socialmente producidas de las formas temporales y de las tendencias globales culturales y económicas que se transmiten por cada vez más puntos del planeta (para análisis específicos sobre esa sociología de los espacios globales, véase, sobre todo, Sassen, 1991, 1998). Es interesante notar, asimismo, el renovado interés que han suscitado conceptos como los de «comunidad» y «participación» en los representantes de todas las sociologías del espacio (por ejemplo, dentro de la perspectiva conflictualista: Leal, 1997; Sevilla y González, 1996; Young, 1990). En ese caso, se puede vislumbrar un nuevo campo de intersección teórica que, aun insistiendo en categorías ya presentes en los albores de la sociología, deja atrás los debates, también clásicos y a veces muy estereotipados, entre lo rural y lo urbano (aunque éstos siguen poseyendo una indudable relevancia en la economía ecológica y en el urbanismo sostenible, áreas a las que la sociología del espacio no puede ser ajena: Martínez Alier, 1994; Naredo, 1994, 1996).

Pero todos estos síntomas, a nuestro juicio, no siempre dejan ver el bosque que hay por detrás de convergencias como las mencionadas a la hora de definir y usar ciertos conceptos de consenso: la distinción y el uso complementario de las distintas concepciones sociológicas del espacio, de las prioridades de análisis enfatizadas por cada corriente teórica y del tipo de interrogantes empíricos que formulan, siempre en la medida en que cada estudio concreto permita y demande explicaciones multidimensionales, y que no se descuiden los factores contextuales, globales y conflictivos de los problemas socioespaciales. Por último, en el plano epistemológico seguiría pendiente, al igual que en otras áreas de las ciencias sociales, el reto de elaborar buenas explicaciones sistémicas (ver, por ejemplo, Bunge, 1999) de los fenómenos socioespaciales, al tiempo que se garantiza la utilidad social de este conocimiento (ver, por ejemplo, Villasante, 1995). El envite está servido y, como se ve, todavía puede dar mucho juego. 


\section{BIBLIOGRAFÍA}

ABBOTT, Andrew (1999): Department \& discipline. Chicago sociology at one hundred, Chicago: The University of Chicago Press.

ALCÁZAR, Miguel; TRABADA, Elías, y CAMACHO, Javier (1993): «Grupos informales y apropiación del espacio urbano», en José C. Lisón Arcal, Espacio y cultura, Madrid: Coloquio, pp. 227-243.

ALFORD, Robert, y FRIEDLAND, Roger (1985): Powers of Theory. Capitalism, the State, and Democracy, Cambridge: Cambridge University Press.

ALGUACIL, Julio (1995): «Veinticinco tesis sobre la complejidad del concepto de lo social en las intervenciones de vivienda pública», en Luis Cortés Alcalá (comp.), Pensar la vivienda, Madrid: Talasa, pp. 70-90.

- (1998): Calidad de vida y praxis urbana. Nuevas iniciativas de gestión ciudadana en la periferia social de Madrid, Madrid: Universidad Complutense de Madrid [Tesis Doctoral, publicada en Siglo XXI-CIS].

BOOKCHIN, Murray (1995 [1991]): The Ecology of Freedom. The Emergence and Dissolution of Hierarchy, Montreal: Black Rose.

BORJA, Jordi, y CASTELLS, Manuel (1997): Local y global. La gestión de las ciudades en la era de la información, Madrid: Taurus-UNCHS.

BRINDLEY, Tim; RYDIN, Yvonne, y STOKER, Gerry (1996): Remaking Planning. The Politics of Urban Change, London: Routledge.

BUNGE, Mario (2000 [1999]): La relación entre la sociología y la filosofía, Madrid: EDAF.

CAMARERO, Luis A. (1993): Del éxodo rural y del éxodo urbano. Ocaso y renacimiento de los asentamientos rurales en España, Madrid: Ministerio de Agricultura, Pesca y Alimentación.

CANTERO, Pedro, et al. (1999): La ciudad silenciada. Vida social y Plan Urban en los barrios del Casco Antiguo de Sevilla, Sevilla: Ayuntamiento de Sevilla.

CASTELLS, Manuel (1986 [1983]): La ciudad y las masas. Sociología de los movimientos sociales urbanos, Madrid: Alianza.

- (1988 [1972]): La cuestión urbana, México: Siglo XXI.

- (1999 [1997]): La era de la información: Economía, Sociedad y Cultura. Vol. 2: El poder de la identidad, Madrid: Alianza.

CASTLEMAN, Craig (1987 [1982]): Los graffiti, Madrid: Hermann Blume.

CONDE, Fernando (1999 [1997]): Urbanismo y ciudad en la aglomeración de Granada. Culturas e identidades urbanas, Sevilla: Junta de Andalucía.

DA COSTA, António Firmino (1999): Sociedade de bairro: dinâmicas sociais da identidade cultural, Oeiras: Celta.

DARKE, Jane (1998): «Búsqueda de una vivienda en la ciudad», en Chris Booth, Jane Darke y Susan Yeandle (eds.), La vida de las mujeres en las ciudades. La ciudad, un espacio para el cambio, Madrid: Narcea, pp. 77-95.

DARKE, Ron (1990): «A city centre for people: popular planning in Sheffield», en J. Montgomery y A. Thornley (eds.), Radical Planning Initiatives: New Directions for Urban Planning in the 1990s, Aldershot: Gower.

DAVIES, W. K. D., y HERBERT, D. T. (1993): Communities within Cities. An Urban Social Geography, London: Belhaven Press. 
DAVIS, Mike (1998): Ecology of Fear. Los Angeles and the Imagination of Disaster, New York: Metropolitan Books.

DEL VALLE, Teresa (1997): Andamios para una nueva ciudad. Lecturas desde la antropología, Madrid: Cátedra.

DÍAZ MUÑOZ, María Ángeles (1989): «Hacia un modelo de diferenciación residencial urbana en España. La aportación del Análisis de Áreas Sociales y la Ecología Factorial», Estudios Territoriales, n. 31, pp. 115-133.

DíEZ NICOLÁS, Juan (1985 [1984]): «Ecología humana y ecosistema social», en Salustiano del Campo (ed.), Tratado de Sociología [vol.1], Madrid: Taurus.

DUNEIER, Mitchell (2001 [1999]): Sidewalk, New York: Farrar, Strauss and Giroux.

DUNLEAVY, Patrick (1980): Urban Political Analysis. The Politics of Collective Consumption, London: Macmillan.

ENCINA, Javier, y ROSA, Montserrat (coords.) (2002): «Más allá de los presupuestos participativos: El Reparto en Las Cabezas de San Juan", en Tomás R. Villasante y Francisco J. Garrido (coords.), Metodologías y presupuestos participativos. Construyendo ciudadanía/3, Madrid: IEPALA-CIMAS, pp. 195-232.

FAINSTEIN, Susan S., y HIRST, C. (1995): «Urban Social Movements», en D. Judge, G. Stoker y H. Wolman (eds.), Theories of Urban Politics, London: Sage.

FORREST, Ray (1991): «The Privatization of Collective Consumption», en M. Gottdiener y Christopher G. Pickvance, (eds.), Urban Life in Transition, California: Sage, pp. 169-195.

GANS, Herbert (2002): «The Sociology of Space: A Use-Centered View», City and Community, vol.1, n. ${ }^{\circ} 4$, pp. 329339.

GIERYN, Thomas F. (2002): «What Buildings Do», Theory and Society, n. ${ }^{\circ}$ 31, pp. 35-74.

GONZÁLEZ DE MOLINA, Manuel, y SEVILLA GUZMÁN, Eduardo (1993): «Ecología, campesinado e historia. Para una reinterpretación del desarrollo del capitalismo en la agricultura», en Manuel González y Eduardo Sevilla (eds.), Ecología, campesinado e historia, Madrid: La Piqueta, pp. 23-129.

GOTTDIENER, Mark, y HUTCHISON, Ray (2000): The New Urban Sociology, Boston: McGraw-Hill.

GUASCH, Óscar (1991): La sociedad rosa, Barcelona: Anagrama.

GUERRA, Isabel (1998): “Grupos sociais, formas de habitat e estrutura do modo de vida», Sociedade e Território, n. ${ }^{\text {s }} 25-26$, pp.118-128.

HARRISON-PEPPER, Sally (1990): Drawing a Circle in the Square. Street Performing in New York's Washington Square Park, New York: University Press of Mississippi.

HARVEY, David (1989 [1973]): Urbanismo y desigualdad social, Madrid: Siglo XXI.

- (1994 [1987]): «Flexible Accumulation trough Urbanization: Reflections on "Post-modernism" in the American City», en Ash Amin (ed.), Post-Fordism. A Reader, Oxford: Blackwell, pp. 361-386.

- (1997 [1996]): Justice, Nature and the Geography of Difference, Oxford: Blackwell.

HERNÁNDEZ AJA, Agustín (dir.) (1997): Análisis urbanístico de barrios desfavorecidos, Madrid: ETSAM.

- (2000): La ciudad de los ciudadanos, Madrid: Ministerio de Fomento.

HOMOBONO, José Ignacio (1994): «Grupos y Asociaciones Amicales. La sociabilidad en Euskal Herria», Inguruak, n. ${ }^{\circ}$, pp. 231-253. 
JORDAN, J. (1998): «The art of necessity: the subversive imagination of anti-road protest and Reclaim the Streets», en G. McKay (ed.), DiY Culture. Party \& Protest in Nineties Britain, London: Verso.

KELLER, Suzanne (1979 [1968]): El vecindario urbano. Una perspectiva sociológica, México: Siglo XXI.

LAMELA VIERA, María del Carmen (1998): La cultura de lo cotidiano. Estudio sociocultural de la ciudad de Lugo, Madrid: Akal.

LEAL, Jesús (1988): «La ciudad y lo urbano», en Román Reyes (dir.), Terminología científico-social. Aproximación crítica, Barcelona: Anthropos, pp. 123-125.

— (1997): «Sociología del espacio: el orden espacial de las relaciones sociales», Política y Sociedad, 25.

LEAL, Jesús, y CORTÉS, Luis (1995): La dimensión de la ciudad, Madrid: CIS-Siglo XXI.

LeGATES, Richard T., y STOUT, Frederic (1998 [1996]): The City Reader, London: Routledge.

LEONARDO, Jon (1989): Estructura urbana y diferenciación residencial: el caso de Bilbao, Madrid: CIS-Siglo XXI.

LOJKINE, Jean (1986 [1977]): El marxismo, el Estado y la cuestión urbana, México: Siglo XXI.

LÓPEZ JIMÉNEZ, Ángela (1998): «El arte de la calle», REIS, n. ${ }^{\circ}$ 84, pp. 173-194.

- (2001): Zaragoza ciudad hablada. Memoria colectiva de las mujeres y los hombres, Zaragoza: Prensas Universitarias de Zaragoza.

LYNCH, Kevin (1981): La buena forma de la ciudad, Barcelona: Gustavo Gili.

LLÉS, Carlos (1991): «Planteamientos y primeros resultados de la investigación sobre formas de vida en Madrid: la ciudad desigual», Ciudad y Territorio, n. ${ }^{\circ} 88$, pp. 101-120.

MARCHIONI, Marco (1994): La utopía posible. La intervención comunitaria en las nuevas condiciones sociales, Tenerife: Benchomo.

MARTÍNEZ ALIER, Joan (1994): De la economía ecológica al ecologismo popular, Barcelona: Icaria.

MARTÍNEZ LÓPEZ, Miguel (1998): «Las ilusiones participativas de la planificación estratégica. Los dilemas históricos y metropolitanos de Medellín (Colombia) ante la transmodernidad», Revista Interamericana de Planificación, vol. XXX, n. ${ }^{\text {s } 117-118, ~ p p . ~ 167-197 . ~}$

- (2001): Urbanismo de rehabilitación no centro histórico de Vigo: unha investigación-social-participativa, Vigo: Universidade de Vigo.

- (2002): Okupaciones de viviendas y centros sociales. Autogestión, contracultura y conflictos urbanos, Barcelona: Virus.

- (2003): «Los movimientos sociales urbanos. Un análisis de la obra de Castells», Revista Internacional de Sociología, $\mathrm{n}^{\circ} 34$, pp. 81-106.

MARTÍNEZ VEIGA, Ubaldo (2000): «Pobreza, exclusión social y segregación espacial», Áreas. Revista de Ciencias Sociales, n. ${ }^{\circ} 19$, pp. 35-50.

MINGIONE, Enzo (1993 [1991]): Las sociedades fragmentadas. Una sociología de la vida económica más allá del paradigma del mercado, Madrid: Ministerio de Trabajo y Seguridad Social.

- (1994): «Polarización, fragmentación y marginalidad en las ciudades industriales», en Anna Alabart, Soledad García y Salvador Giner (comps.), Clase, poder y ciudanía, Madrid: Siglo XXI, pp. 97-122. 
NAREDO, José Manuel (1994): «El funcionamiento de las ciudades y su incidencia en el territorio», Ciudad y Territorio. Estudios Territoriales, n. ${ }^{\text {os }} 100-101$, pp. 233-249.

- (1996): «Sobre el origen, el uso y el contenido del término sostenible», en AA.VV., Primer catálogo español de buenas prácticas, Madrid: Ministerio de Fomento, pp. 21-28.

PANIAGUA, José León (1995): «Balance y perspectivas de la política de vivienda en España», en Luis Cortés Alcalá (comp.), Pensar la vivienda, Madrid: Talasa, pp. 45-69.

PARK, Robert E. (1999 [1925]): «La ciudad: sugerencias para la investigación del comportamiento humano en el medio ambiente urbano», en Víctor Urrutia, Para comprender qué es la ciudad. Teorías sociales, Estella: EVD.

PICKVANCE, Christopher G (1984): «The Structuralist Critique in Urban Studies», en Michel P. Smith (ed.), Cities in Transformation. Class, Capital and the State, London: Sage.

- (1985): «The rise and fall of urban movements and the role of comparative analysis», Environment and Planning D: Society and Space, vol. 3.

- (1986): «Concepts, contexts and comparison in the study of urban movements: a reply to M. Castells», Environment and Planning D: Society and Space, vol. 3.

- (1995): «Marxist Theories of Urban Politics», en D. Judge, G. Stoker y H. Wolman (eds.), Theories of Urban Politics, London: Sage.

- (2003): «From Urban Social Movements to Urban Movements: A review and Introduction to a Symposium on Urban Movements», International Journal of Urban and Regional Research, 27.1, pp. 102-109.

PRETECEILLE, Edmond (1994): «Paradojas políticas de las reestructuraciones urbanas, globalización de la economía y localización de lo político», en Anna Alabart, Soledad García y Salvador Giner (comps.), Clase, poder y ciudanía, Madrid: Siglo XXI, pp. 61-96.

PRUIJT, Hans (2003): «Is the institutionalization of urban movements inevitable? A comparison of the opportunities for sustained squatting in New York City and Amsterdam», International Journal of Urban and Regional Research, 27.1, pp. 133-157.

ROBERTS, Bryan R. (1991): «Household Coping Strategies and Urban Poverty in a Comparative Perspective», en M. Gottdiener y Christopher G. Pickvance (eds.), Urban Life in Transition, California: Sage, pp. 135-168.

RODRÍGUEZ, Arantxa, y MARTíNEZ, Elena (2001): «Del declive a la revitalización: oportunidades y límites de las nuevas políticas urbanas en Bilbao», Ciudad y Territorio. Estudios Territoriales, vol. XXXIII, n. ${ }^{\circ}$ 129, pp. 441-459.

RUIZ BALLESTEROS, Esteban (2000): Construcción simbólica de la ciudad. Política local y localismo, Madrid: Miño y Dávila.

SASSEN, Saskia (1991): The Global City: New York, London, Tokio, Princeton: Princeton University Press.

- (1998): Globalization and Its Discontents, New York: New Press.

SAUNDERS, Peter (1986 [1981]): Social Theory and the Urban Question, London: Hutchinson.

SAVAGE, M., y WARDE, A. (1993): Urban Sociology, capitalism and modernity, London: Macmillan.

SCHWENDINGER, Herman, y SCHWENDINGER, Julia R. (1974): The sociologists of the chair. A radical analysis of the formative years of north american sociology 1883-1922, New York: Basic Books.

SCOTT, James C. (1998): Seeing like a State. How Certain Schemes to Improve Human Condition Have Failed, New Haven: Yale University Press. 
SEMPERE, Pedro (1977): Los muros del posfranquismo, Madrid: Castellote.

SEVILLA GUZMÁN, Eduardo, y GONZÁLEZ DE MOLINA, Manuel (1996): «Sobre la agroecología: algunas reflexiones en torno a la agricultura familiar en España», en María Antonia García de León (ed.), El campo y la ciudad (Sociedad rural y cambio social), Madrid: Ministerio de Agricultura, Pesca y Alimentación, pp. 155-197.

STOKER, Gerry (1995): «Regime Theory and Urban Politics», en D. Judge, G. Stoker y H. Wolman (eds.), Theories of Urban Politics, London: Sage.

TELLO, Enric (1996): «Barcelona Estalvia Energia. Una propuesta de democracia participativa para el cambio de modelo de ciudad», Ecología Política, n. ${ }^{11}$.

URRUTIA, Víctor (1999): Para comprender qué es la ciudad. Teorías sociales, Estella: EVD.

VARELA, Julia, y ÁLVAREZ-URÍA, Fernando (1989): Sujetos frágiles. Ensayos de sociología de la desviación, Madrid: FCE.

VILLASANTE, Tomás R. (1984): Comunidades locales. Análisis, movimientos sociales y alternativas, Madrid: IEAL.

- (1995): Las democracias participativas. De la participación ciudadana a las alternativas de la sociedad, Madrid: HOAC.

VILLASANTE, Tomás R., et al. (1989): Retrato de chabolista con piso. Análisis de redes sociales en la remodelación de barrios de Madrid, Madrid: IVIMA-SGV-Alfoz.

WIRTH, Louis (1988 [1938]): «Urbanismo como forma de vida», en Mercedes Fernández Martorell, Leer la ciudad. Ensayos de antropología urbana, Barcelona: Icaria.

YOUNG, Iris Marion (2000 [1990]): La justicia y la política de la diferencia, Madrid: Cátedra. 


\section{ABSTRACT}

A wide recent research is theoretically reviewed according to any of the four main traditions in the sociology of space following the proposals of Peter Saunders and Víctor Urrutia in urban sociology. Firstly, we define the different sociological conceptions of space pointing out how they transcend the strict «urban» issues. Secondly, we examine the theoretical priorities of analysis and the interpretative styles of empirical researches while classifying them into any of the main streams. Finally, it will be argued the actual complementarity between some essential features of the four traditions under the transversal relevance of conflictual and holistic approaches in each research.

Key words: Sociology of Space, Urban Sociology, Theories. 